\title{
La Imposición sobre la Renta para las cooperativas financieras: tendencias en Argentina, Colombia y España
}

(The Income Tax for Financial Cooperatives: Trends in Argentina, Colombia and Spain)

\author{
Graciela Lara Gómez ${ }^{1}$ \\ Universidad Autónoma de Querétaro (México) \\ Pilar Alguacil Marí \\ Universidad de Valencia (España)
}

Sumario: 1. Introducción. 2. Marco teórico. 3. Metodología. 4. Discusión. 4.1. Los ingresos tributarios en Argentina, Colombia y España. 4.2. Las cooperativas financieras y su fiscalidad. 4.3. La imposición sobre la renta en las cooperativas de Argentina, Colombia y España. 4.3.1. El Impuesto a las Ganancias en Argentina. 4.3.2. El Impuesto Sobre la Renta en Colombia. 4.3.3. El Impuesto Sobre Sociedades en España. 4.4. Comparación de la Imposición a la Renta en Argentina, Colombia y España. 5. Conclusiones. 6. Referencias bibliográficas. 7. Anexo legislativo.

Summary: 1. Introduction. 2. Theoretical framework. 3. Methodology. 4. Discussion 4.1. Tax revenues in Argentina, Colombia and Spain. 4.2. Financial cooperatives and their taxation. 4.3. Income tax in cooperatives in Argentina, Colombia and Spain. 4.3.1. The Income Tax in Argentina. 4.3.2. The Income Tax in Colombia. 4.3.3. The Corporation Tax in Spain. 4.4. Comparison of Income Taxation in Argentina, Colombia and Spain. 5. Conclusions. 6. Bibliographic references. 7. Legislative annex.

1 Profesora-Investigadora en la Universidad Autónoma de Querétaro, México. Doctora en Estudios Organizacionales por la Universidad Autónoma Metropolitana y doctoranda del programa de Doctorado en Economía Social (cooperativas y entidades no lucrativas) de la Universidad de Valencia. Correo electrónico: glara@uaq.mx

2 Catedrática de Derecho Financiero y Tributario en la Universidad de Valencia. Correo electrónico: pilar.alguacil@uv.es. El presente trabajo se desarrolla en el marco de la investigación del proyecto ECONOMIA COLABORATIVA, ECONOMÍA SOCIAL Y BIENESTAR, DER2015-65519-C2-1-R (MINECO/FEDER). 
Resumen: Con el presente artículo se buscó esclarecer si el fomento a las cooperativas financieras en atención a su función de social, actividades y características, es congruente con el tratamiento tributario para la imposición a la renta, que se otorga en Argentina, Colombia y España. Para tal efecto, se recurrió a teóricos que proponen incorporar incentivos en las leyes tributarias, argumentando razones de justicia social y equidad, pues dicen que existen justificaciones económicas políticas y sociales para que determinados sujetos sean liberados del impuesto. Con el análisis comparado, se estableció que existe una tendencia a gravar a tales sociedades, lo que ha conducido a que paulatinamente se estén suprimiendo los beneficios tributarios que antes se les otorgaban.

Palabras clave: Cooperativas, renta, gravamen, naciones.

Abstract: The aim of this article is to clarify if the promotion of financial cooperatives, according with their social function, activities and characteristics, is consistent with the tax treatment for the taxation of income, which is granted in Argentina, Colombia and Spain. For this purpose, the theorists who propose the inventions in the tax laws are compiled, arguing reasons of social justice and equity, since they say that there are justifications of the policies and social networks so that the subjects are released from the tax. With the comparative analysis, we identify that there is a tendency to tax of such societies, what has led to the gradual reduction of the tax benefits that were previously granted to them.

Keywords: Cooperatives, rent, tax, nations. 


\section{Introducción}

Analizar las tendencias que sobre el tratamiento fiscal se asigna a las cooperativas financieras ${ }^{3}$ en Argentina, Colombia y España, resulta fundamental para comprender las razones políticas, sociales y económicas que los legisladores toman en consideración al momento de reformar las leyes en materia de la imposición sobre la renta, ya sea para reducir o eliminar las cargas tributarias o establecer gravámenes que en ocasiones pueden ser iguales o superiores a los que se aplican a las empresas de capitales.

No puede ignorarse que las cooperativas contribuyen decididamente al desarrollo de las naciones, lo que puede ser observado a través de los más de 100 millones de puestos de trabajo, así como de la movilización de la economía mediante actividades de producción, consumo y servicios ( $\mathrm{ACl}, 2016)$. Asimismo, participan en la dinámica económica mundial a través de los ingresos agregados por un importe de 1.6 millones de dólares estadounidenses que generan las 300 cooperativas más importantes, cifra que es semejante al Producto Interno Bruto (PIB) de España (OIT, 2015).

La contribución de las cooperativas se ubica en su dinámica económica y social, que se despliega a partir de las iniciativas comunitarias que es el lugar en donde emergen los emprendimientos locales que dan vida a muchas comunidades en situación de rezago, desigualdad, desempleo y pobreza (Manterola, 2012; Lara Gómez \& Rico Hernández, 2011). En este sentido, se explica que el fomento e impulso que debe darse a las cooperativas no es un tema únicamente de política pública, sino que va más allá, pues es un asunto de justicia social que es reconocido en las Constituciones de diversos países (Alguacil Marí, 2010; Merino Jara, 2009), por lo que sus preceptos debieran incorporarse en las legislaciones tributarias que regulan los impuestos a la renta.

Para cumplir con el objetivo del estudio, fueron seleccionados dos países de América Latina (Argentina y Colombia), los que fueron elegidos por el dinamismo en sus reformas tributarias. Se eligió también a España, por ser un país europeo con amplia tradición en el tema cooperativo y que constituye un referente digno de ser comparado con los sistemas latinoamericanos.

3 La expresión 'cooperativa financiera' se aplica indistintamente en este documento, para referirse a las cooperativas de ahorro y crédito, cooperativas o cajas de crédito. Asimismo, se emplea esta acepción para referirse a las cooperativas que en Argentina, Colombia y España, se dedican a la intermediación financiera, principalmente a través del otorgamiento de préstamos y la captación de ahorro e inversión. 
Con lo mencionado, en un primer momento se revisaron los aportes teóricos que justifican la inclusión de incentivos tributarios en legislaciones de los países y que potencialmente pueden beneficiar a las sociedades cooperativas. Luego, se describió la metodología que incluyó el objetivo general y la aplicación del método comparativo. Posteriormente, se llevó a cabo un análisis de la realidad legal de las cooperativas en los países estudiados, frente a la imposición sobre la renta.

Finalmente, surgieron las evidencias que apuntan a que en el tratamiento que en los tres países se otorga a las cooperativas, tiene como punto de inflexión, la expectativa del Estado de gravarlas para fines de la imposición a la renta de manera similar que a las empresas de capitales.

\section{Marco teórico}

Las Constituciones de los países contemplan la obligatoriedad de contribuir para los gastos del Estado, por lo que la manutención y mejoras públicas serían inviables sin la existencia de tributos. En este sentido, Arrioja Vizcaíno (2014) expone las justificaciones doctrinarias para que un Estado pueda exigir impuestos, por ejemplo, con la Teoría de la Relación de la Sujeción se justifica la exigencia a los ciudadanos de participar con el pago de contribuciones económicas para cubrir el gasto público, pretensión que nace del simple sometimiento a la soberanía de los que detentan el poder público, se reciban o no beneficios. Pero también, se puede aludir a la Teoría del Beneficio Equivalente, la que postula que los tributos tienen como fin sufragar los servicios que el Estado presta, por lo que los mismos deben significar un beneficio equivalente a las contribuciones que se hayan entregado.

Independientemente de las justificaciones doctrinarias que obligan a un sujeto a contribuir con el gasto público, es un hecho que las constituciones otorgan tal facultad al Estado, ya que la recaudación que se haga de los impuestos u otros ingresos de carácter fiscal, tendrá efectos positivos o negativos en la vida social y económica de un país.

En este sentido, Flores Zavala (2004, p. 63) indica que los impuestos son:

«Una aportación que deben dar los miembros del Estado, por un imperativo derivado de la convivencia en una sociedad políticamente organizada, para que el Estado se encuentre en la posibilidad de realizar las atribuciones que se le han señalado.» 
La existencia de impuestos desde la perspectiva económica incluye un mecanismo por el que el Estado recaude fondos para financiar los proyectos públicos (Mankiw, 2012). Por tanto, los impuestos representan algo inherente a la sociedad y significan una inversión que hace un asociado (contribuyente) para conformar un patrimonio común que será distribuido por el Estado a la sociedad a través de bienes y servicios. Con ello, surge la justicia legal, que es la condición para que se consume la justicia distributiva (Hincapié Gómez, 2014).

Entre los impuestos, se encuentran los denominados directos, los que gravan esencialmente el ingreso y representan una fuente significativa de percepciones fiscales para los Estados. Los impuestos directos según Margain Manautou (1983), tienen la característica de no ser repercutibles, esto quiere decir que no se pueden trasladar a otros sujetos, lo que implica que el impuesto incida en la renta o utilidades obtenidas por el contribuyente o sujeto pasivo. Por tanto, los impuestos directos en ningún caso podrán ser recuperados de otras personas o trasmitidos.

Rodríguez Lobato (2011, p. 7) dice que, el patrimonio se verá afectado por el pago de impuestos, lo que hace que surja un instrumento de política pública: los incentivos tributarios. Con ellos, se busca equilibrar las cargas entre los diferentes sujetos pasivos. Por tanto, desde la perspectiva de Mankiw (2012) pueden definirse que los incentivos son: "algo que induce a las personas a actuar y puede ser una recompensa o un castigo».

En consecuencia, los incentivos tributarios representan instrumentos de política pública, que son incorporados en las legislaciones y demás regulaciones de tipo fiscal con una finalidad específica centrada en la aspiración de impulsar el desarrollo, estimular la economía o bien, por razones de índole social. Por tanto, las exenciones son una forma de incentivo que «no representan, por tanto, un privilegio y, como tales no contradicen el principio de igualdad tributaria» (De la Garza, 2012, p. 519).

Por su parte, Alguacil Marí (2010) y Merino Jara (2009) indican que los incentivos deben proporcionar beneficios fiscales congruentes con los principios constitucionales. Jiménez \& Podesta (2009) indican que son beneficios fiscales o incentivos las exenciones o exoneraciones temporales, la reducción de tasas, los incentivos a la inversión y el diferimiento de créditos fiscales.

En consecuencia, no puede ignorarse que la función de los tributos es vital para sostener el gasto público, pero también lo es, acentuar la importancia de la función social de las instituciones y sus organizaciones, que conjuntamente con el Estado contribuyen a una mejor convi- 
vencia. Por lo que el otorgamiento de incentivos es beneficioso, y a veces, necesario para fomentar la existencia de organizaciones con fines sociales, como es el caso de las cooperativas. Por tanto, su especificidad depende según Fici (2015) de las leyes que le confieran una identidad específica y la preserven, pues solo así se podrá afirmar que existen diferencias entre los diversos tipos de sociedades, pues de no hacerlo será complicado justificar un trato específico.

En este sentido, Martínez Charterina (2015), Fici (2015), Pastor del Pino (2012), Cracogna (2004) y Rodrigo Ruiz (2003) manifiestan los aportes que las cooperativas hacen a las comunidades, indicando que llevan a cabo sus actividades con apoyo en los principios y valores que han sido aprobados por la Alianza Cooperativa Internacional, por tanto, la autoayuda, la autorresponsabilidad, la democracia, la igualdad, la equidad, la solidaridad, la ética, la honestidad, la transparencia, la responsabilidad y la vocación social de sus socios, son fundamentales en la gestión cooperativa.

Igualmente, Pastor del Pino (2012) afirma que las cooperativas ayudan al desarrollo sostenible de su entorno, favoreciendo la redistribución de la renta y el acceso a los medios de producción y/o consumo, dado que dichas organizaciones se han adaptado a los constantes cambios en la sociedad, pasando de una posición antiempresarial a su participación activa en el mercado. Rodrigo Ruiz (2003) abona a la discusión diciendo que, en gran medida el patrimonio social de las cooperativas es obtenido por el esfuerzo de los miembros y luego es revertido a la comunidad, por lo que resulta congruente que contribuyan en menor medida a los gastos públicos, ya que queda plenamente justificado su aporte a la sociedad y por tanto, debe ser un sujeto pasivo con un tratamiento fiscal que otorgue incentivos tributarios.

Fici $(2015)$ sostiene que en los preceptos constitucionales de diversos países, se concede a las cooperativas la característica de realizar una función social, por lo que para que las normas sean consideradas como legitimas a la luz del principio de igualdad, es necesario que posean una identidad jurídica diferente a la del resto de las sociedades, esto significa que el régimen jurídico requiere de una idoneidad específica propia de las cooperativas, debiendo considerar disposiciones congruentes con su finalidad económica-social.

No obstante, las notables contribuciones de las cooperativas, su legitimación a través de preceptos de orden Constitucional y de las evidencias que justifican el otorgamiento de incentivos tributarios para su desarrollo. Cracogna (2004) advierte que se ha venido deteriorando el marco tributario para las cooperativas, debido a la eliminación paulatina de los incentivos, lo que las ha obligado a migrar hacia nuevos ho- 
rizontes como consecuencia de una situación financiera que roza la subsistencia.

Así, Cracogna (2005) afirma que se ha venido generando una abierta persecución fiscal contra las cooperativas que no tiene precedentes, lo que ha tenido como consecuencia, tratamientos impositivos desfavorables, inclusive para los países tradicionalmente beneficiaba al sector. Propone como explicación, que las políticas públicas en materia tributaria, suelen ser favorables cuando las cooperativas son incipientes y se incrementa la presión tributaria cuando éstas han alcanzado un mayor nivel de desarrollo.

Por tanto, puede afirmarse que la tendencia de imponer tributos a las cooperativas no es ajena de los países europeos como España, las que siempre han sido gravadas por el Impuesto Sobre Sociedades, si bien con un régimen especial, con una cuota tributaria algo menor. Ahora bien, ya desde el año 2000, a partir de denuncias presentadas por asociaciones de empresarios de Madrid y Cataluña, se empezó a cuestionar la posible inequidad por este tratamiento fiscal particular para las cooperativas, esto ha sido reiterado por algunos otros sectores de la Unión Europea, por el pretendido trato diferenciado para dichas sociedades; considerando que podrían constituir ayudas de Estado prohibidas por el artículo 107 del Tratado de Funcionamiento de la Unión Europea (Alguacil Marí, 2010, 2003; Rodrigo Ruiz, 2010; Aguilar Rubio, 2012).

En contra de esta tendencia, diversos autores pugnan por un tratamiento fiscal que otorgue incentivos fiscales a las cooperativas. En este sentido Pastor del Pino (2012), Alguacil Marí $(2010,2003)$ y Merino Jara (2009) proponen un esquema tributario amparado en argumentos consistentes, que se apoyen en la justicia contributiva y en la idoneidad del modelo social. Como resultado, los tributos deben ser congruentes con la aplicación de los principios constitucionales, por lo que concuerdan en que el trato diferenciado para las cooperativas no implica un tratamiento preferente, sino por el contrario, confirma la máxima de justicia.

Por tanto, Aguilar Rubio (2015) dice que una política fiscal como la mencionada previamente puede significar una herramienta poderosa para el fomento y desarrollo del modelo cooperativo. De tal manera que, puede advertirse que las cooperativas son necesarias e importantes para las naciones, ya que en múltiples ocasiones sustituyen al Estado en su actividad o coadyuvan en programas de carácter público en favor de sus asociados y las comunidades. Por lo que no es posible concebir un tratamiento similar con las empresas de capitales, pues la equidad incluye reconocer las diferencias contributivas y los aportes socialmente necesarios que dichas sociedades realizan. 


\section{Metodología}

Se considera que para que las cooperativas sean favorecidas en su desarrollo, hace falta que en materia fiscal se fijen incentivos tributarios, los que deben ser entendidos como el estímulo que proporciona el Estado a los sujetos pasivos que se ubican en determinadas hipótesis jurídicas, para la promoción de actividades consideradas de interés público.

Por tanto, el objetivo del presente trabajo buscó determinar si el fomento a las cooperativas financieras en Argentina, Colombia y España, en atención a su función de social, actividades y características, es congruente con el tratamiento que las leyes en materia de la imposición a la renta se les asigna.

Para el estudio se privilegió el método de investigación comparativo de las ciencias jurídicas (Tamayo y Salmorán, 2007), a efecto de contrastar las convergencias y divergencias doctrinarias, así como los diferentes tratamientos incluidos en las legislaciones fiscales de los países seleccionados. Con todo ello, se buscó describir la realidad y confrontarla con los sistemas tributarios que rigen en cada nación. De manera que, fue necesario formular un marco comparativo para destacar las coincidencias y divergencias en las legislaciones tributarias que regulan la imposición sobre la renta en los tres países.

\section{Discusión}

A continuación, se analiza la situación que prevalece en cuanto a los niveles de recaudación y las políticas adoptadas en los tres países estudiados. Asimismo, se agregan algunas particularidades de las leyes en el tópico cooperativo y se cierra con el estudio comparado de las legislaciones tributarias respecto al gravamen a la renta, destacando las bases y tasas del impuesto.

\subsection{Los ingresos tributarios en Argentina, Colombia y España}

Según la OCDE et al. (2018), en los países de América Latina y el Caribe el promedio de ingresos tributarios ha venido creciendo del $15.8 \%$ en 1990 a $22.7 \%$ en 2016 . Los tributos que contribuyeron al incremento de los ingresos tributarios en dicha región, fueron los impuestos a la renta y al consumo, particularmente los que gravan el valor agregado. No obstante, en dichos países la recaudación todavía se 
encuentra por debajo del promedio de la OCDE, que en 2016 fue del $34.3 \%$, lo que pone de manifiesto que aunque se han realizado esfuerzos para elevar las percepciones tributarias de los países, estos no han sido suficientes para alcanzar a las naciones con mejor desempeño económico.

Respecto al nivel de recaudación como proporción del PIB en Argentina, Colombia y España, pudo establecerse lo siguiente (OECD, 2017; OCDE et al., 2018).

- Argentina ha mostrado un buen posicionamiento con un 31.3\% (datos a 2016), que es cercano al promedio de los países de la OCDE y muy por encima de los países latinoamericanos;

- Por su parte, Colombia presenta un 19.8\%, muy por debajo del promedio de las países de la OCDE que es del 34.3\%,

- En contraste, en España durante 2016, la recaudación tributaria revelaba un nivel del $33.2 \%$, contra el $36.5 \%$ de 2012 , lo que ha significado una importante caída en los ingresos fiscales para esta nación, ya que actualmente se encuentra por debajo del promedio de los países miembros de la OCDE.

Con los datos mencionados, puede verse que el país con mejor posicionamiento en cuanto a recaudación es España, seguido porla nacion Argentina y finalmente, con una amplia brecha hacia la baja se encuentra Colombia.

En este sentido, la OCDE, CEPAL, CIAT \& BID (2017) expresan que la relación que existe entre los impuestos y el PIB, está reflejado por la recaudación de los ingresos tributarios que los gobiernos obtienen para financiar los bienes y servicios públicos, así como para invertir en infraestructura. Por lo que dichos organismos consideran que incrementar las percepciones fiscales es fundamental para garantizar que una nación emerja económicamente. Es por ello, que la presión de los organismos internacionales hacia los países emergentes ha sido intensa, promoviendo la adopción de políticas fiscales - que proponen eliminar los incentivos fiscales-, que son consideradas como convenientes para incrementar la recaudación y así enfrentar los retos de un mundo globalizado.

Entre los países de América Latina existe un creciente interés por participar en organismos internacionales, entre otras razones, buscando legitimar su presencia como nación en una economía de mercado. Tal situación ha llevado a los países a concretar acciones e introducir reformas a sus legislaciones para cumplir con los requerimientos y recomendaciones que dichos organismos hacen, situación que puede ser percibida a partir de las últimas reformas tributarias que se han efectuado en los países de Argentina y Colombia. 
Por ejemplo, en Argentina el presidente ha manifestado su intención de que el país ingrese como miembro de la OCDE (2017 a), lo que justifica en la búsqueda del fortalecimiento y el posicionamiento económico nacional, razón por la que se han adoptado diversas medidas en su política fiscal. Enunciativamente se pueden mencionar tres políticas para fortalecer la recaudación y reducir el gasto público:

- Asegurar la sostenibilidad fiscal, revisando el gasto público,

- Eliminar subsidios elevados no focalizados, y

- Ampliar la base de contribuyentes.

De la misma manera, en Colombia se han introducido políticas públicas para fortalecer su sistema tributario y su viabilidad económica, lo que ha sido fundamental para apuntalar su reciente ingreso a la OCDE. Previamente, dicho país recibió diversas recomendaciones en materia fiscal, entre las que pueden mencionarse las siguientes (OCDE, 2015 a):

- Efectuar una reforma integral del sistema tributario a efecto de incrementar la equidad, el crecimiento y la recaudación,

- Disminuir la evasión de impuestos a través del fortalecimiento de la administración tributaria y el incremento de las sanciones, y

- Ampliar la base del impuesto a la renta de sociedades de forma gradual.

Por lo que se refiere a España, el organismo internacional (OCDE, 2014) ha dictado recomendaciones para mejorar el desempeño del país y fortalecer su sistema tributario, entre ellas destacan las siguientes:

- Reducir las exenciones en el Impuesto sobre el Valor Añadido, el Impuesto Sobre Sociedades y el Impuesto Sobre la Renta,

- Ampliar la base impositiva para los sujetos del Impuesto Sobre Sociedades, y

- Eliminar los regímenes especiales, que se encuentran vigentes para pequeñas y medianas empresas.

Como puede advertirse, las recomendaciones de la OCDE para los tres países son similares, dado que se sugiere la reducción de exenciones y subsidios, además de realizar reformas que conduzcan a incrementar los impuestos, así como ampliar la base impositiva y el número de contribuyentes sujetos a los tributos, lo que ha implicado la reforma a las leyes, para eliminar los incentivos y fortalecer el sistema recaudatorio.

Es importante señalar que las prescripciones dictadas, fueron acatadas por la nación colombiana en su reciente reforma tributaria, donde se incluyó un importante incremento y ajuste a gravámenes como los 
referidos a la renta y al consumo. Igualmente, Argentina adoptó las recomendaciones de la OCDE, cuyo efecto se observó mediante el intento de reformar integralmente la legislación que regula el gravamen a la renta, con la finalidad de eliminar exoneraciones a algunas sociedades - entre ellas a las cooperativas-.

\subsection{Las cooperativas financieras y su legislación}

La relevancia de las cooperativas en los contextos nacionales se ha expresado a través de acciones en el ambito social y económico, por lo que para valorar su relevancia, es necesario conocer la conformación del sector por su tamaño y figuras juridicas que lo integran.

En primer término se menciona a Argentina, cuyo sector se integra de 290 cooperativas de credito (no supervisadas), dos cajas de crédito supervisadas y un banco cooperativo (Vuotto, 2014). Mientras tanto en Colombia, se cuenta con 181 cooperativas autorizadas para ejercer la actividad financiera, así como cinco cooperativas financieras, un banco cooperativo, un banco de propiedad cooperativa y una compañía de financiamento de propiedad cooperativa (Confecoop, 2017). En lo que corresponde a España, el sector está compuesto por 83 cooperativas de crédito (Belmonte Ureña, 2007).

Las sociedades mencionadas se rigen por legislaciones específicas (de tipo cooperativo), que poseen características centradas en el fomento de las actividades sociales y económicas en beneficio de la colectividad. Tales normas tienen su origen en disposiciones constitucionales o leyes específicas, que dictan la obligación que tiene el Estado de impulsar su fomento.

No obstante, que las normas jurídicas citadas tienen la misma finalidad, pueden percibirse ciertas diferencias que obedecen a su contexto geográfico, político y social, pues debe recordarse que cada nación determina la forma de regirse. Al respecto Gadea Soler, Sacristán Bergia \& Vargas Vasserot (2009) dicen que en países como los latinoamericanos, las legislaciones cooperativas son usadas como instrumentos políticos e ideológicos y no como una forma de hacer empresa. Esto es contrastante con la concepción jurídica que dicen prevalece en España, donde se ha considerado el rol de la economía de mercado y la realidad de tener que competir con otras entidades privadas, pues como lo ha señalado Pastor del Pino (2012), las cooperativas han transitado de una posición antiempresarial a su participación activa en el mercado.

En cuanto a la legislación cooperativa en Argentina y España, se han visto en la necesidad de formular normas jurídicas específicas para 
regular la actividad de la actividad de intermediación financiera que realizan las cooperativas; es por lo que funcionan en forma paralela, supletoria o complementaria, otras leyes que dictan preceptos específicos para su actividad. De tal manera que, enseguida pueden verse las legislaciones de la materia que se encuentran vigentes en los tres países (Tabla 1).

Tabla 1

Legislación para las cooperativas financiera

\begin{tabular}{|c|l|l|l|}
\hline \multicolumn{1}{|c|}{ País } & \multicolumn{1}{|c|}{ Argentina } & \multicolumn{1}{c|}{ Colombia } & \multicolumn{1}{c|}{ España } \\
\hline $\begin{array}{c}\text { Legislación } \\
\text { cooperativa }\end{array}$ & $\begin{array}{l}\text { Ley No. 20337 } \\
\text { (1973). } \\
\text { Ley de Coopera- } \\
\text { tivas. }\end{array}$ & $\begin{array}{l}\text { Ley 79 (1988), } \\
\text { por la que se ac- } \\
\text { tualiza la Legis- } \\
\text { lación Coopera- } \\
\text { tiva. }\end{array}$ & $\begin{array}{l}\text { Ley 27 (1999) de } \\
\text { Cooperativas. }\end{array}$ \\
\hline $\begin{array}{c}\text { Legislación } \\
\text { particular sobre } \\
\text { Cooperativas } \\
\text { Financieras }\end{array}$ & $\begin{array}{l}\text { de Entidades Fi- } \\
\text { nancieras. } \\
\text { Ley 26.173. Ca- } \\
\text { jas de Crédito } \\
\text { Cooperativas. }\end{array}$ & $\begin{array}{l}\text { Normatividad fi- } \\
\text { nanciera. }\end{array}$ & $\begin{array}{l}\text { Ley 13/1989, } \\
\text { del 26 de mayo. } \\
\text { Cooperativas de } \\
\text { Crédito (BOE de } \\
\text { 31) }\end{array}$ \\
\hline
\end{tabular}

Fuente: Elaboración propia, con base en las leyes mencionadas.

En las normas para las cooperativas se incluyen pautas como la finalidad en beneficio de la sociedad, destacando la característica no lucrativa que se encuentra contenida solamente en la ley colombiana. En la Constitución española se contempla el mandato de promover a las cooperativas, lo que sugiere la obligación del Estado de apoyarlas. En el caso de Colombia, la legislación considera que este tipo de sociedades poseen la característica no lucrativa, lo que es una clara diferencia contra las empresas de capitales, lo que significaría que por su finalidad deberían quedar liberadas del pago del tributo a la renta. En la Constitución Argentina no se establecen disposiciones expresas para el fomento específico de las cooperativas.

Pero, ¿cómo se define a la cooperativa en las normas jurídicas particulares? Al respecto, en Argentina se dice que: «Las cooperativas son entidades fundadas en el esfuerzo propio y la ayuda mutua para organizar y prestar servicios (...) (Ley 20337, 1973, p. 1). 
Como puede observarse, a pesar de que no se incluye explícitamente la característica no lucrativa, se contempla su propósito centrado en la ayuda mutua, que es un elemento diferenciador de las empresas de capitales; por lo que en un sentido de equidad, no sería válido tratar igual a personas jurídicas que son esencialmente desiguales.

Por su parte, en la legislación cooperativa de Colombia se indica lo siguiente:

«Es cooperativa la empresa asociativa sin ánimo de lucro, en la cual los trabajadores o los usuarios, según el caso, son simultáneamente los aportantes y los gestores de la empresa, creada con el objeto de producir o distribuir conjunta y eficientemente bienes o servicios para satisfacer las necesidades de sus asociados y de la comunidad en general.» (Ley 79, 1988, p. 3-4)

De la simple lectura del texto legal se desprende que las cooperativas son entidades 'sin animo de lucro', por lo que no son bajo ningún argumento, semejantes a las empresas lucrativas. En consecuencia, dichas sociedades debieran ser incentivadas con exenciones fiscales y otros apoyos.

De la misma manera, las leyes españolas recogen la finalidad de las cooperativas en su definición; para ejemplificar, se retoma la contenida en la Ley de Cooperativas del País Vasco, la que dice:

«La cooperativa es una empresa que tiene por objeto prioritario la promoción de actividades económicas y sociales de sus miembros y la satisfacción de sus necesidades con la participación de los mismos, observando los principios cooperativos y atendiendo a la comunidad de su entorno.» (Gadea Soler, Sacristán Bergia \& Vargas Vasserot, 2009, p. 23)

Como puede observarse, en las tres definiciones citadas se prioriza la satisfacción de necesidades individuales y colectivas. Además se agrega como un elemento central, la contribución al desarrollo a través de la práctica de valores y principios que se apoyan en la ayuda mutua y la asociación, siendo estos los pilares necesarios para el logro de fines socialmente necesarios, pues como bien lo indica Aguilar Rubio (2015) una política fiscal que reconozca la valía de las cooperativas, significará un instrumento eficaz para el fomento y desarrollo del modelo cooperativo. 


\subsection{La imposición a la renta en las cooperativas de Argentina, Colombia y España}

De acuerdo con la OCDE et al. (2018), los impuestos a la renta se encuentran entre las principales fuentes de ingresos fiscales de la mayor parte de los países en el mundo. Tales tributos se regulan de manera específica en legislaciones que forman parte del sistema fiscal de cada nación. En lo que corresponde a los gravámenes al ingreso para las sociedades en general, pudo establecerse que son reconocidos con denominaciones diversas, siendo la más común la abreviatura ISR, referida al Impuesto Sobre la Renta.

Las denominaciones con las que se identifica a los diferentes gravámenes a la renta en los tres países son:

- Impuesto a las Ganancias en Argentina,

- Impuesto Sobre la Renta en Colombia, e

- Impuesto Sobre Sociedades en España.

Precisamente, las legislaciones fiscales que regulan el Impuesto a las Ganancias y el Impuesto Sobre la Renta, en Argentina y Colombia respectivamente, han sufrido importantes reformas.

- En Argentina se intentó gravar a las cooperativas en los mismos términos que a las empresas de capitales, situación que afortunadamente no se llevó a cabo dicha modificación, no obstante, se aplica un impuesto sobre el capital, denominada Contribución extraordinaria sobre el Capital de Cooperativas y Mutuales de Ahorro, de Crédito y/o Financieras, de Seguros y/o Reaseguros (Ley 27.486, 2019) la novedosa legislación establece una carga fiscal de entre el $3 \%$ y $4 \%$.

- En Colombia, se han venido ampliando las bases para el pago de impuestos, modificado las cargas impositivas y se han reducido los incentivos fiscales para las cooperativas financieras.

- En España, se ha notado la tendencia de gravar a las cooperativas financieras, de la misma manera que a las empresas lucrativas (por los resultados cooperativos) y que a las entidades de crédito (por los resultados extracooperativos).

Por lo que se confirma que la tendencia tributaria en los tres países apunta a equiparar el tratamiento fiscal de las cooperativas financieras, como si se tratara de empresas con fines eminentemente de lucro, ignorando que existe una diferenciación importante entre ambas, ya que las cooperativas tienen una función social que beneficia a las comunidades, mientras que las sociedades de capitales se guían exclusiva- 
mente por el lucro. Además de que en ocasiones las cooperativas sustituyen al Estado en actividades que le son propias, en beneficio de la comunidad.

Es así, que la existencia legal de las cooperativas financieras queda contemplada en normas jurídicas específicas y su tratamiento tributario se integra en legislaciones como la que se refiere al gravamen a la renta, las que se analizan en el siguiente apartado.

\subsubsection{El Impuesto a las Ganancias en Argentina}

La Ley No. 27.430 de fecha 29 de diciembre de 2017, que regula el Impuesto a las Ganancias, entró en vigor en enero de 2018 y ha sufrido reformas posteriores durante el primer semestre de 2019. De manera que en el presente documento se identificará al dispositivo legal como Ley del Impuesto a las Ganancias (2018). Dicha legislación en su artículo $1 .{ }^{\circ}$ contempla a los sujetos del impuesto, los que son las personas humanas, las personas jurídicas y demás previstas en la ley.

En la legislación de Argentina se contempla como objeto del impuesto a las ganancias obtenidas por los sujetos, entre las que se incluyen: los rendimientos, rentas o enriquecimientos susceptibles de una periodicidad que implique la permanencia de la fuente que los produce y su habilitación, así como los beneficios por la enajenación de bienes muebles amortizables (artículo 2 de la Ley del Impuesto a las Ganancias, 2018).

En el artículo 69 se menciona que las sociedades de capital quedan gravadas por sus ganancias netas imponibles a la tasa del 25\%. Entre dichas sociedades se encuentran sociedades mercantiles lucrativas y las cooperativas constituidas en Argentina. El dispositivo legal se transcribe como sigue:

«Art. 69. Las sociedades de capital, por sus ganancias netas imponibles, quedan sujetas a las siguientes tasas:

a) al veinticinco por ciento (25\%):

1. Las sociedades anónimas —incluidas las sociedades anónimas unipersonales-, las sociedades en comandita por acciones, en la parte que corresponda a los socios comanditarios, y las sociedades por acciones simplificadas del Título III de la ley 27.349, constituidas en el país.

2. Las sociedades de responsabilidad limitada, las sociedades en comandita simple y la parte correspondiente a los socios comanditados de las sociedades en comandita por acciones, en todos los casos cuando se trate de sociedades constituidas en el país. 
3. Las asociaciones, fundaciones, cooperativas y entidades civiles y mutualistas, constituidas en el país, en cuanto no corresponda por esta ley otro tratamiento impositivo.

(...) (Ley del Impuesto a las Ganancias, 2018, s.p.). ${ }^{4}$

Nótese que en este artículo se equipará a las cooperativas con las empresas de capitales. No obstante, en el numeral 3 se indica que son sociedades de capital las cooperativas, pero se agrega una expresión adicional: (...) «en cuanto no corresponda por esta ley otro tratamiento impositivo» (artículo 69 de la Ley del Impuesto a las Ganancias, 2018, s.p.). De manera que en la propia legislación se integra otra disposición (artículo 20) que exenta del gravamen a la renta a las cooperativas, la que prescribe lo siguiente:

«Art. 20. Están exentos del gravamen:

(...)

d) Las utilidades de las sociedades cooperativas de cualquier naturaleza (...)»

Como puede verse en la intención del legislador se puede observar el deseo de equiparar a las cooperativas de todo tipo como si se tratará de empresas de capitales, pero ala encontrarse una norma especial, favorable a dichas sociedades, es la exoneración del tributo la que prevalece. En consecuencia, las cooperativas financieras se encuentran eximidas del pago del Impuesto a las Ganancias.

Como consecuencia y con la intención de gravar aunque fuera de forma mínima a las cooperativas, se publicó la Ley 27.486 (2019) que grava el capital de tales sociedades, aplicando dos tasas el $3 \%$ y $4 \%$ de acuerdo con el monto resultante de capital. De manera que, se aplica el 3\% cuando el monto del capital no exceda de 100 millones de pesos argentinos y cuando exceda de dicha cantidad se pagará el $4 \%$ más una cuota de 3 millones de pesos argentinos.

Cabe señalar que un gravamen similar al mencionado en el párrafo anterior ya existía y se aplicaba a las cooperativas a una tasa menor (del $2 \%)$.

Por lo anterior, los gravámenes contemplados para los fines del Impuesto a las Ganancias, que están vigentes para 2018 son:

- Sociedades lucrativas, la tasa del 25\%.

- Cooperativas financieras. Exentas.

4 La letra cursiva es de las autoras. 
Por lo analizado, se puede concluir que en el ánimo de los legisladores persiste el ánimo de retirar las exoneraciones para las cooperativas, ignorando los aportes económicos y sociales de dichas sociedades, por lo que la Contribución extraordinaria sobre el Capital de Cooperativas y Mutuales de Ahorro, de Crédito y/o Financieras, de Seguros y/o Reaseguros (Ley 27.486, 2019), es solo un ejemplo de esta tendencia del Estado.

\subsubsection{El Impuesto Sobre la Renta en Colombia}

Las reformas al régimen tributario en Colombia se concretaron a través de la Ley 1819 (2016), las que fueron publicadas el 29 de diciembre del mismo año y cuya entrada en vigor fue el $1 .^{\circ}$ de enero de 2017. En tal dispositivo se incluyó la reforma fiscal estructural, que modificó los gravámenes y otras disposiciones en materia del Impuesto Sobre la Renta, donde se menciona que son sujetos del impuesto, las personas naturales y las jurídicas (sociedades).

Las empresas lucrativas o de capitales, están obligadas al pago del Impuesto Sobre la Renta aplicando una tasa del 33\%, más una sobretasa del $4 \%$. Dicho gravamen estará vigente en 2018, pero a partir de 2019 y en los años subsecuentes la tasa vigente será la fijada en 33\% (Ley 1819, 2016).

Precisamente, es en el artículo 19-4 de la Ley 1819 (2016) que se considera como obligadas al pago del Impuesto Sobre la Renta a las cooperativas, además se incluye a sus asociaciones, uniones, ligas centrales, organismos de grado superior de carácter financiero, las asociaciones mutualistas, instituciones auxiliares del cooperativismo, confederaciones cooperativas, incluidas en la legislación cooperativa y que sean vigiladas por alguna superintendencia u organismo de control. Dicha norma contempla un Régimen Tributario Especial, que ofrece beneficios sobre el gravamen que se impone a las demás personas jurídicas (sociedades lucrativas). En consecuencia, las cooperativas causan el impuesto sobre los beneficios netos o excedentes que obtengan, aplicando la tarifa única especial del $20 \%$. La disposición indica que tal impuesto será tomado en su totalidad del Fondo de Educación y Solidaridad a que se refiere el artículo 54 de la Ley 79 (1988).

Además de lo aludido, según el artículo 160 de la Ley 1819 (2016) que adiciona el artículo 364-3 del Estatuto Tributario, las cooperativas podrán ser excluidas del régimen especial, entre otras circunstancias: cuando incumplan lo dispuesto por la legislación cooperativa y lo establecido en el artículo 19-4 del mismo Estatuto tributario (Ley 1819, 2016), o bien, destinen a una finalidad distinta el excedente o bene- 
ficio neto y omitan la presentación de declaraciones o lo hagan extemporáneamente. De darse las causales citadas, la cooperativa estará obligada a tributar en los términos establecidos para las empresas de capitales y se suspenderá la aplicación del régimen especial. No obstante, pasados tres años podrán solicitar una nueva calificación a efecto de regresar al denominado Régimen Tributario Especial.

Es importante señalar que durante 2018, la tarifa del impuesto vigente se calculará como se describe enseguida:

«PARÁGRAFO TRANSITORIO SEGUNDO. En el año 2018 la tarifa a la que se refiere el inciso 10 de este artículo será del quince por ciento $(15 \%)$. Además, el cinco por ciento $(5 \%)$ del excedente, tomado en su totalidad del Fondo de Educación y Solidaridad de que trata el artículo 54 de la Ley 79 de 1988, deberá ser destinado de manera autónoma por las propias cooperativas a financiar cupos y programas en instituciones de educación superior públicas autorizadas por el Ministerio de Educación Nacional.»(Ley 1819, 2016, p. 73)

De tal manera que el Impuesto Sobre la Renta para las personas jurídicas, se calculará considerando las siguientes tasas (Ley 1819, 2016):

- Para las personas jurídicas lucrativas (empresas de capitales), una tasa del 33\% más una sobretasa del $4 \%$, que resulta en un gravamen neto del $37 \%$.

- Para las personas jurídicas denominadas cooperativas (empresas no lucrativas), se aplicará una tasa del 15\%, adicionada del 5\%. En lo sucesivo, es decir a partir de 2019 se aplicará la tasa del $20 \%$.

Como puede verse, en Colombia existe un tratamiento diferenciado para las cooperativas, ya que están obligadas al pago del impuesto a una tasa menor que la aplicable a las empresas de capitales. No obstante, hasta antes de la reforma el impuesto que debían cubrir era del $10 \%$, lo que claramente representa una afectación a las finanzas de tales sociedades.

Además de mencionar las tasas y su vigencia, es importante explicar cómo se integra la base del impuesto. Para tal efecto, en el artículo 19-4, párrafo segundo del Estatuto Tributario, se indica que las cooperativas efectuarán el cálculo del beneficio neto o excedente según la legislación y normativas en materia cooperativa, las que se refieren a la determinación del resultado en términos de las normas contables vigentes, es decir considerar los ingresos, disminuidos de los gastos o costos. 
Adicionalmente, se aclara que las reservas legales a que están obligadas las cooperativas no podrán ser registradas como un gasto para los fines del cálculo del gravamen a la renta. También se explica que tales sociedades, estarán sujetas a la retención por concepto de rendimientos financieros y se les excluirá de la posibilidad de la determinación de renta presuntiva y pago de anticipos del gravamen sobre la renta (Ley 1819, 2016).

\subsubsection{El Impuesto Sobre Sociedades en España}

En España la del Impuesto Sobre Sociedades, fue publicada el 28 de noviembre de 2014 y modificada por última ocasión el 28 de junio de 2017. Dicho impuesto es un tributo de carácter directo y personal que en el territorio español grava la renta de las sociedades y otras entidades jurídicas (artículos 1 y 2). El Impuesto Sobre Sociedades (Ley 27, 2014) rige conjuntamente con otras leyes, como la Ley 20 (1990) sobre el Régimen Fiscal de las Cooperativas, que establece las particularidades para el cálculo y pago del impuesto sobre la renta de las sociedades cooperativas.

En cuanto a lo que se grava, se indica en el artículo 4 de la que el hecho imponible es la obtención de la renta, independientemente de su fuente $u$ origen. Respecto a la tasa del impuesto, en el artículo 29 se contempla que el gravamen general será del $25 \%$. Asimismo, según la norma el hecho imponible se constituye a partir de la obtención de la renta, sea cual fuere su fuente u origen (artículo 4). La base gravable será la determinada en el periodo por el que se paga el impuesto, disminuida de las bases imponibles negativas de periodos anteriores y considerando los gastos necesarios para la obtención del ingreso (Ley 27, 2014).

Las cooperativas financieras en España, presentan un tratamiento fiscal para fines de la imposición a la renta, que tienen poca o nula diferenciación con los que se aplican a otras sociedades, ya que las sociedades lucrativas causan el impuesto a la tasa del $25 \%$, mientras que las instituciones de crédito (no cooperativas, ni cajas de crédito) pagan el $30 \%$

En este orden de ideas, en el artículo 29 numeral 2, se establece la tasa aplicable a las cooperativas, señalando dos supuestos, el primero se refiere a la tasa del $20 \%$ que corresponde a las cooperativas fiscalmente protegidas y por los resultados extracooperativas tributan a la tasa del 25\%; en segundo lugar, se encuentran las cooperativas de crédito y cajas rurales que pagan el impuesto a la tasa del $25 \%$ y por los resultados extracooperativos al $30 \%$. El texto legal puede verse a continuación: 
«Tributarán al 20 por ciento las sociedades cooperativas fiscalmente protegidas, excepto por lo que se refiere a los resultados extracooperativos, que tributarán al tipo general. Las cooperativas de crédito y cajas rurales tributarán al tipo general, excepto por lo que se refiere a los resultados extracooperativos, que tributarán al tipo del 30 por ciento.» (Ley 27, 2014, p. 46)

En consecuencia, de conformidad con el artículo 16 de la Ley 20 (1990) para determinar la base imponible se considerarán por separado los resultados cooperativos y los extracooperativos. En los primeros se consideran los ingresos obtenidos por la actividad cooperativizada, mientras que para los segundos serán los rendimientos extracooperativos y los incrementos y disminuciones patrimoniales.

En este sentido, Aguilar Rubio (2012) ha puntualizado que el régimen fiscal español para las cooperativas presenta exigencias tales, que desmotivan cualquier iniciativa económica, por lo que prefieren cumplir con sus obligaciones según el régimen general, evitando llevar contabilidad separada de las operaciones con los terceros no socios.

Por lo mencionado, el tratamiento contemplado para el Impuesto Sobre Sociedades, que es aplicable de conformidad con la y la Ley 20 (1990) a las sociedades lucrativas y a las cooperativas financieras, es el siguiente:

- Las sociedades lucrativas tributan a la tasa del $25 \%$.

- Las cooperativas financieras tributarán al $25 \%$ por sus resultados cooperativos y por los extracooperativos a la tasa del $30 \%$.

- Las entidades de crédito (no cooperativas, ni cajas de ahorro) pagan el $30 \%$.

Como puede observarse, a pesar de que las sociedades de capitales y las cooperativas financieras se encuentran gravadas a la tasa del $25 \%$, las cooperativas tienen una carga administrativa adicional al estar obligadas a separar sus resultados.

Es así que por los resultados cooperativos, las cooperativas de crédito aplican la tasa del $25 \%$ que es la misma que se menciona para las empresas de capitales, mientras que por los resultados extracooperativos, el tratamiento fiscal en cuanto a la tasa del impuesto es el mismo que se asigna a las entidades de crédito, es decir, el 30\%.

Es importante indicar que cuando en las cooperativas se acuerden retornos cooperativos que se acrediten a los socios, dichos ingresos pagarán el gravamen a la renta, como si se tratase de dividendos, para tal efecto se tendrán en cuenta las disposiciones del Impuesto Sobre la Renta de las Personas Físicas. Además, de conformidad con la Ley 20 
(1990) las cooperativas estarán obligadas a efectuar a sus socios y a terceros las retenciones que procedan.

Por lo mencionado, se puede observar que se está incumpliendo el mandato Constitucional de fomento a las cooperativas, ya que no se contemplan exoneraciones para el gravamen a la renta, lo que es ciertamente inequitativo, ya que no es posible que se esté otorgando un trato similar a sujetos que son desiguales.

\subsection{Comparación de la Imposición a la Renta en Argentina, Colombia y España}

Diversos autores (Rodrigo Ruiz, 2003; Alguacil Marí, 2010; Merino Jara, 2009) indican, que de ninguna forma puede concebirse la aplicación de un tratamiento uniforme a las cooperativas y a las empresas de capitales, ya que existen justificaciones constitucionales y sociales que deben impulsar a los legisladores a otorgar un trato diferenciado, es decir, estimular la actividad de las cooperativas otorgándoles incentivos fiscales.

Las evidencias que derivan del análisis muestran una tendencia a gravar a las cooperativas financieras, no solamente por su potencial económico o su tamaño, como lo indica Cracogna (2005), sino que son producto de la adopción de políticas públicas que son justificadas por la necesidad que tienen los países de incrementar la recaudación, disminuyendo los incentivos fiscales, pero que también son motivadas por el acatamiento de lineamientos dictados por organismos internacionales como la OCDE.

Lo anterior puede ser verificado en la norma fiscal en Argentina que contempla un gravamen para las cooperativas en el mismo rango que a las empresas de capitales $25 \%$, disposición que finalmente no se aplica por la existencia de una disposición particular que las exonera. Cabe señalar, que en general las cooperativas contribuyen a través de la Contribución extraordinaria sobre el Capital de Cooperativas y Mutuales de Ahorro, de Crédito y/o Financieras, de Seguros y/o Reaseguros.

En lo que corresponde a Colombia, con la reforma de 2016 que entró en vigor en 2017, se incrementó el gravamen para las cooperativas que antes era del $10 \%$ y ahora es del $20 \%$. Aunque debe reconocerse que dicha tasa está por debajo de la que se aplica a las empresas de capitales que es del 33\% más la sobretasa del $4 \%$. Por lo que para las cooperativas financieras persiste un régimen especial que reduce el gravamen general y que representa un tratamiento favorable. 
En España el régimen fiscal para las cooperativas financieras está fijado a dos tasas el $25 \%$ por los resultados cooperativos que es similar al que se aplica a las empresas de capitales y la tasa del $30 \%$ por los resultados extracooperativos que es equivalente al que se impone a las entidades de crédito, lo que de ninguna manera representa un tratamiento favorable.

Esencialmente, las leyes Argentina y Colombia se han reformado recientemente como efecto de una reforma integral que busca incrementar la recaudación y abatir la evasión fiscal. Paralelamente, en la legislación de España data de 2014 y no presenta reformas posteriores para las cooperativas de crédito.

Los gravámenes expresados pro tasas de las imposiciones a la renta de los tres países, se muestran en la Tabla 2.

\section{Tabla 2}

Comparativo de Impuestos a la Renta en Argentina Colombia y España

\begin{tabular}{|c|c|c|}
\hline País & $\begin{array}{l}\text { Impuesto a la Renta para } \\
\text { sociedades lucrativas }\end{array}$ & $\begin{array}{l}\text { Impuesto a la Renta para } \\
\text { las cooperativas financieras }\end{array}$ \\
\hline Argentina & Tasa del $25 \%$. & Exentas. \\
\hline Colombia & $\begin{array}{l}\text { Tasa del } 33 \% \text { más una sobre- } \\
\text { tasa del } 4 \% \text {. }\end{array}$ & Tasa del $20 \%$. \\
\hline \multirow{2}{*}{ España } & $\begin{array}{l}\text { Tasa del } 25 \% \text { sociedades lu- } \\
\text { crativas (excepto instituciones } \\
\text { de crédito). }\end{array}$ & $\begin{array}{l}\text { Tasa del } 25 \% \text { por los resulta- } \\
\text { dos cooperativos. }\end{array}$ \\
\hline & $\begin{array}{l}\text { Tasa del } 30 \% \text { instituciones de } \\
\text { crédito (excepto cooperativas } \\
\text { y cajas rurales). }\end{array}$ & $\begin{array}{l}\text { Tasa del } 30 \% \text { por los resulta- } \\
\text { dos extracooperativos. }\end{array}$ \\
\hline
\end{tabular}

Fuente: elaboración propia.

Derivado de la comparación de las diferentes disposiciones tributarias, se puede concluir que la tendencia que están adoptando los países, apunta a gravar a las cooperativas con fines de recaudación, eliminando de esta manera los incentivos que se traducían en exenciones y reducciones. Esto implica una importante inequidad, que ha sido ampliamente discutida en la doctrina y por la Corte, estableciendo que debe darse un trato diferenciado a los sujetos cuando se encuentren en situaciones desventajosas, ya que la equidad implica reconocer que los diferentes sujetos pueden ser diferentes. 
Finalmente, se reitera que, por sus características, las cooperativas debieran ser beneficiadas con incentivos fiscales, a través de exenciones y reducciones de impuestos, ya que de esta manera se cumpliría el mandato constitucional de fomentarlas, lo que hoy en día no está ocurriendo.

\section{Conclusiones}

La relevancia de estudiar la tributación de las cooperativas, es un tema central para comprender las tendencias que en materia de los impuestos al ingreso prevalecen en las naciones. El incremento o ajuste a los diferentes tratamientos apunta a ser resultado de la influencia de organismos internacionales - como la OCDE - que buscan introducir una mayor presión fiscal en las estructuras impositivas, a efecto de que la recaudación nacional se vea incrementada sustancialmente. Esto no significa que gravar sociedades como las cooperativas financieras sea la solución, pues el aporte monetario puede no impactar sensiblemente en las finanzas públicas y por el contrario desmotivan la acción social de dichas sociedades, ya que el pago del impuesto representa una merma en los ingresos y en consecuencia menores beneficios para los asociados.

Con las reformas a las leyes y los tratamientos tributarios vigentes, se está ignorando la contribución social y económica que las cooperativas dan a las comunidades. Con lo que se confirma lo que ha señalado Alonso Sánchez (2009) y Aguilar Rubio (2012), sobre que el régimen fiscal para las pequeñas y medianas empresas puede resultar, en muchos de los casos más atractivo para las cooperativas que su propio esquema tributario. Además, es necesario recordar que la promoción de las cooperativas es un mandato contemplado en las Constituciones y en las leyes nacionales, por lo que su aporte debiera ser reconocido con el impulso a políticas de orden fiscal, a efecto de proporcionar un trato diferenciado, pero no preferente, respecto del que aplica al resto de las sociedades con fines de lucro.

En definitiva, debe reflexionarse en la contribución que las cooperativas hacen al desarrollo económico y social de los países, la que debiera ser la justificación más sólida para su promoción y otorgamiento de incentivos tributarios. 


\section{Referencias bibliográficas}

ACl. 2016. Hechos y cifras del cooperativismo en las Américas y el mundo. Desde http://www.aciamericas.coop/Hechos-y-cifras-del-cooperativismo.

AGUILAR RUBIO, Marina. 2016. «El régimen fiscal de las cooperativas y el Derecho de la Unión Europea». Boletín de la Asociación Internacional de Derecho Cooperativo, 50: 49-71. doi: http://dx.doi.org/10.18543/baidc-502016pp49-71.

AGUILAR RUBIO, Marina. 2015. "Los principios cooperativos en la legislación tributaria». CIRIEC España. Revista jurídica de economía social y cooperativa, (27), págs. 373-400. ISSN 1577-4430. Desde https://dialnet.unirioja. es/servlet/articulo?codigo $=5383000$

AGUILAR RUBIO, Marina. 2012. "La evolución de la posición de las Instituciones de la Unión Europea frente régimen fiscal especial de las cooperativas». En Lejarriaga, G., Martín López, S. y Muñoz García, A. (Dirs.). 40 años de historia de las empresas de participación. Madrid: Escuela de Estudios Cooperativos de la UCM.

ALGUACIL MARÍ, María Pilar. 2003. «Tratamiento fiscal de las cooperativas a la luz del régimen europeo de Ayudas de Estado». CIRIEC-España. Revista jurídica de economía social y cooperativa, ISSN 1577-4430, n. ${ }^{\circ} 14,2003$, pp. 131-181. Desde https://dialnet.unirioja.es/servlet/articulo?codigo=760704

ALGUACIL MARÍ, María Pilar. 2010. "Condicionantes del régimen de ayudas de Estado en la fiscalidad de cooperativas». CIRIEC-España, Revista de Economía Pública, Social y Cooperativa, (69), 27-52. Desde https://dialnet. unirioja.es/ejemplar/260465

ALONSO RODRIGO, Eva y Santa Cruz Ayo, Iñaki. 2016. «Identidad, competitividad y creación de empleo: retos para una nueva fiscalidad de las cooperativas de trabajo asociado». Boletín de la Asociación Internacional de Derecho Cooperativo, 50: 73-101. doi: http://dx.doi.org/10.18543/baidc50-2016pp73-101.

ALONSO SÁNCHEZ, Rosalía. 2009. «La legislación española sobre las cooperativas y sociedades laborales: Una respuesta adecuada a las necesidades del sector». CIRIEC-España, Revista de Economía Pública, Social y Cooperativa, no. 20/2009, pags. 9-41. Desde https://dialnet.unirioja.es/servlet/articulo? codigo $=3140035$

ARRIOJA VIZCAINO, Adolfo. 2014. Derecho Fiscal. México: Themis Editores.

ATXABAL RADA, Alberto. 2018. «Los impuestos personales sobre el capital en las cooperativas y en sus socios en el País Vasco». Boletín de la Asociación Internacional de Derecho Cooperativo, 52: 137-166. doi: http://dx.doi. org/10.18543/baidc-52-2018pp137-166.

ATXABAL RADA, Alberto. 2017. "Las consecuencias fiscales de la baja de los socios cooperativistas que sean personas físicas». Boletín de la Asociación Internacional de Derecho Cooperativo, 51: 209-230. doi: http://dx.doi. org/10.18543/baidc-51-2017pp209-230.

BELMONTE UREÑA, Luis Jesús. 2007. El Sector de Cooperativas de Crédito en España: un estudio por Comunidades Autónomas. Análisis de su eficiencia 
y dimensión (1995-2003). Sevilla: Consejo Económico y Social de Andalucía.

CONFECOOP. 2017. Sector cooperativo con actividad financiera diciembre 2017. Observatorio Cooperativo, No. 44. Desde http://confecoop.coop/ wp-content/uploads/2018/03/Boletin-Observatorio-44-activ-fin.pdf.

CRACOGNA, Dante. 2004. "Las cooperativas frente al régimen tributario». En Cracogna, D. (coordinador) Las cooperativas y los impuestos en el Mercosur. Buenos Aires: Intercoop.

CRACOGNA, Dante. 2005. "Las cooperativas y los impuestos. Las experiencias del Mercosur». Desde http://www.aciamericas.coop/IMG/ RTcoopimpdante.pdf

DE LA GARZA, Sergio Francisco. 2012. Derecho Financiero Mexicano. México: Editorial Porrúa.

$\mathrm{FICl}$, A. 2015. «La función social de las cooperativas: notas de derecho comparado». REVESCO: Revista de Estudios Cooperativos. ISSN: 1885-8031, pp. 77-98.

FLORES ZAVALA, E. 2004. Elementos de Finanzas Públicas Mexicanas. México: Editorial Porrúa.

GADEA SOLER, Enrique, Fernando Sacristán Bergia \& Carlos Vargas Vasserot. 2009. Régimen jurídico de la Sociedad Cooperativa del siglo XXI. Realidad actual y propuestas de reforma. Madrid: Editorial Dykinson, S.L.

HINCAPIE GÓMEZ, María Viviana. 2014. «Los Principios Rectores del Derecho Tributario». Nuevo Derecho. Vol. 10, No. 15, julio-diciembre de 2014, pp. 47-54-ISSN: 2011-4540. Envigado-Colombia. Desde https://dialnet. unirioja.es/servlet/articulo?codigo $=5549096$

JIMÉNEZ, Juan Pablo \& Andrea Podestá. 2009. «Inversión, incentivos fiscales y gastos tributarios en América Latina». Santiago de Chile: CEPAL. Recuperado de https://www.cepal.org/publicaciones/xml/2/35732/Serie_MD_77. pdf

LARA GÓMEZ, Graciela. 2018. «La equidad horizontal en la tributación de las cooperativas en México». Boletín de la Asociación Internacional de Derecho Cooperativo, 53: 251-253. doi: http://dx.doi.org/10.18543/baidc-532018pp251-253.

LARA GÓMEZ, Graciela. 2018. "Los incentivos tributarios para las cooperativas financieras de Colombia, Costa Rica y México». REVESCO: Revista de Estudios Cooperativos, 127: 159-180. doi: http://dx.doi.org/10.5209/ REVE.59772

LARA GÓMEZ, Graciela \& Amalia Rico Hernández. 2011. «La contribución de las cooperativas de ahorro y crédito al desarrollo local en Querétaro, México». REVESCO: Revista de Estudios Cooperativos. 106: 121-149.

MANKIW, Gregory. 2012. Principios de economía. México: Cengage Learning Editores.

MANTEROLA, Juan. 2012. Una mirada al cooperativismo y su participación en redes para el desarrollo. México: La Red de la Gente.

MARGAIN MANAUTOU, Emilio. 1983. Introducción al Estudio del Derecho Tributario Mexicano. México: Universidad Autónoma de San Luis Potosí. 
MARTÍNEZ CHARTERINA, Alejandro. 2015. "Las cooperativas y su acción sobre la sociedad». REVESCO: Revista de Estudios Cooperativos. N. ${ }^{\circ}$ 117-MONOGRÁFICO: Las sociedades cooperativas construyen un mundo mejor, pp. 34-49. ISSN: 1885-8031. Desde http://revistas.ucm.es/index.php/REVE/ article/view/48144/0

MERINO JARA, Isaac. 2009. «El vigente régimen fiscal de las cooperativas a la luz de las ayudas de Estado». CIRIEC-España, Revista de Economía Pública, Social y Cooperativa, octubre, págs.109-126. ISSN 1989-6816. Desde https://www.redalyc.org/pdf/174/17413043005.pdf

OCDE. 2014. Estudios económicos de la OCDE España, septiembre 2014. Desde http://www.oecd.org/eco/surveys/Spain-Overview-Spanish.pdf

OCDE. 2015a. Estudios económicos de la OCDE Colombia. Desde www.oecd. org/eco/surveys/Overview_Colombia_ESP.pdf

OCDE. 2017a. Estudios económicos de la OCDE Argentina. Estudio económico multidimensional, julio de 2017. Desde http://www.oecd.org/countries/ argentina/Argentina-2017-OECD-economic-survey-overview-ESP.pdf

OCDE. 2017 b. Revenue Statisrics: 1965-2016. Paris: OECD Publishing.

OCDE, CEPAL, CIAT \& BID. 2017. Estadísticas tributarias en América Latina y el Caribe 1990-2016. Paris: OECD Publishing.

OCDE, et al. 2018. Estadísticas tributarias en América Latina y el Caribe 2018, OECD Publishing, Paris. http://dx.doi.org/10.1787/rev_lat_car-2018-en-fr

OIT. 2015. Las cooperativas y los objetivos de desarrollo sostenible, Debate sobre el desarrollo después de 2015. Desde http://www.ilo.org/empent/ Publications/WCMS_307228/lang--es/index.htm.

PASTOR DEL PINO, María del Carmen. 2012. "Competitividad de las cooperativas y régimen fiscal específico: el incentivo por objetivos». CIRIEC-ESpaña. Revista jurídica de economía social y cooperativa. ISSN 1577-4430, n. ${ }^{\circ} 23,2012$, pp. 97-120. Desde https://dialnet.unirioja.es/servlet/articulo? codigo $=4202679$

RODRIGO RUIZ, Marco Antonio. 2017. «Consideraciones en torno al establecimiento de un régimen tributario común para las entidades de la economía social». REVESCO. Revista de Estudios Cooperativos, 125: 187-212. doi: http://dx.doi.org/10.5209/REVE.57064.

RODRIGO RUIZ, Marco Antonio. 2010. "Consideraciones sobre el régimen fiscal de las cooperativas. Problemas actuales y líneas de reforma». CIRIEC-España, Revista de Economía Pública, Social y Cooperativa. ISSN 0213-8093, No. 69, pp. 9-25. Desde https://www.redalyc.org/ pdf/174/17418700002.pdf

RODRIGO RUIZ, Marco Antonio. 2003. «Mandato constitucional de fomento y fiscalidad de las cooperativas». CIRIEC-España, Revista de Economía Pública, Social y Cooperativa, núm. 47, noviembre, 2003, ISSN edición impresa: 0213-8093. ISSN edición electrónica: 1989-6816, pp. 199-219. Desde http://www.redalyc.org/articulo.oa?id=17404720

RODRÍGUEZ LOBATO, Raúl. 2011. Derecho Fiscal. México: Oxford.

TAMAYO Y SALMORÁN, Rolando. 2007. «Teoría Jurídica y «Derecho Comparado» Una Aproximación y Un Deslinde». Isonomia: Revista de Teoría 
y Filosofía del Derecho. No. 27. Octubre, 2007, p 29-49. Recuperado de http://biblioteca.org.ar/libros/141192.pdf.

VUOTTO, Mirta. 2014. «La Economía Social y las cooperativas en la Argentina». Voces en el Fenix. No. 38, septiembre, 2014. Desde http://www. vocesenelfenix.com/content/la-economía-social-y-las-cooperativas-en-laargentina

\section{Anexo legislativo}

LEY 1819, 2016. Por medio de la cual se adopta una reforma tributaria estructural, se fortalecen los mecanismos para la lucha contra la evasión y la elusión fiscal, y se dictan otras disposiciones. Congreso de Colombia. Desde https://www.dian.gov.co/impuestos/Reforma\%20Tributaria\%20 Estructural/Documento \%20Ley\%201819\%20del\%2029\%20de\%20 Diciembre\%20de\%202016\%20-\%20Reforma\%20Tributaria \% 20 Estructural.pdf

LEY 20, 1990. Régimen Fiscal de las Cooperativas. Jefatura de Estado. España. Desde https://www.boe.es/buscar/pdf/1990/BOE-A-1990-30735consolidado.pdf

LEY 20337, 1973. Ley de Cooperativas. Poder Ejecutivo Nacional. Desde https://www.argentina.gob.ar/normativa/ley-20337-18462/actualizacion

LEY 23.427, 1986. Creación del Fondo de Educación y Promoción Cooperativa. Argentina: Ministerio de Justicia y Derechos Humanos, Presidencia de la Nación. Desde http://servicios.infoleg.gob.ar/infoleglnternet/ anexos/20000-24999/22268/texact.htm

LEY 27, 2014. Impuesto Sobre Sociedades. Jefatura de Estado. España. Desde https://www.boe.es/buscar/pdf/2014/BOE-A-2014-12328-consolidado.pdf

LEY 27.486, 2019. Contribución extraordinaria sobre el Capital de Cooperativas y Mutuales de Ahorro, de Crédito y/o Financieras, de Seguros y/o Reaseguros. Poder Legislativo Nacional. Desde https://www.boletinoficial.gob. ar/detalleAviso/primera/199661/20190108

LEY 79, 1988. Por la cual se actualiza la legislación Cooperativa. Congreso de Colombia. Ley 79, 1988. Por la que se actualiza la legislación Cooperativa. Recuperado de http://www.alcaldiabogota.gov.co/sisjur/normas/Norma1. jsp?i=9211

LEY DEL IMPUESTO A LAS GANANCIAS, 2018. Información Legislativa, Presidencia de la nacion. Desde http://servicios.infoleg.gob.ar/infoleglnternet/ anexos/40000-44999/44911/texact.htm 


\section{Derechos de autor}

El Boletín de la Asociación Internacional de Derecho Cooperativo es una revista de acceso abierto lo que significa que es de libre acceso en su integridad inmediatamente después de la publicación de cada número. Se permite su lectura, la búsqueda, descarga, distribución y reutilización legal en cualquier tipo de soporte sólo para fines no comerciales y según lo previsto por la ley; sin la previa autorización de la Editorial (Universidad de Deusto) o el autor, siempre que la obra original sea debidamente citada (número, año, páginas y DOI si procede) y cualquier cambio en el original esté claramente indicado.

\section{Copyright}

The International Association of Cooperative Law Journal is an Open Access journal which means that it is free for full and immediate access, reading, search, download, distribution, and lawful reuse in any medium only for non-commercial purposes, without prior permission from the Publisher or the author; provided the original work is properly cited and any changes to the original are clearly indicated. 